\title{
A NOTE ON ENTREPRENEURIAL RISK, CAPITAL MARKET IMPERFECTIONS, AND HETEROGENEITY
}

\author{
YULEI LUO \\ University of Hong Kong \\ LIUTANG GONG \\ Peking University \\ HENG-Fu Zou \\ The World Bank \\ CUFE \\ Shenzhen University \\ and \\ Wuhan University
}

Empirical evidence shows that entrepreneurs hold a large fraction of wealth, have higher saving rates than workers, and face substantial uninsurable entrepreneurial and investment risks. This paper constructs a heterogeneous-agent general equilibrium model with uninsurable entrepreneurial risk and capital-market imperfections to explore the implications of uninsurable entrepreneurial risk for wealth distribution and aggregate activity in an incomplete market economy. It is shown that entrepreneurial risk can substantially affect both the wealth distribution and the macroeconomy.

Keywords: Wealth Distribution, Idiosyncratic Entrepreneurial Risk, Incomplete Capital Markets

\section{INTRODUCTION}

What role do uninsurable entrepreneurial risk and capital market imperfections play in shaping the wealth distribution in the economy? What are the impacts of financial development on the level and volatility of aggregate output and capital? In this paper, we construct a heterogeneous-agent dynamic stochastic general

\footnotetext{
An earlier version of this paper was circulated under the title "Uninsurable Entrepreneurial Risk, Capital Market Imperfections, and Heterogeneity in the Macroeconomy." We thank Chris Sims, Pierre-Olivier Gourinchas, Per Krusell, and Eric Young, as well as seminar participants at Princeton University and Memphis University for helpful suggestions and comments. Gong thanks the National Science Foundation for Distinguished Young Scholars (\#70725006) for financial support. The Fortran code solving the benchmark model is available from the corresponding author by request. Address correspondence to: Yulei Luo, School of Economics and Finance, The University of Hong Kong, Hong Kong; e-mail: yluo@econ.hku.hk.
} 
equilibrium model to address these important macroeconomic questions quantitatively. The main features of this model are that occupational choice is endogenous, capital markets are incomplete in the sense that idiosyncratic risks cannot be fully insured, and contracts between borrowers and lenders are imperfectly enforceable.

The literature has typically found that simple models based on standard and identical preferences and on uninsurable shocks to labor income cannot account for the observed U.S. Gini coefficient of 0.803 on wealth. ${ }^{1}$ For example, Aiyagari (1994) finds considerably less wealth concentration in a model with only idiosyncratic labor earnings uncertainty; Krusell and Smith (1998) find the same in models with both aggregate and idiosyncratic shocks. Among the infinite horizon models that try to reproduce the wealth distribution in the U.S. data, two kinds of models have performed well. One is the stochastic- $\beta$ model by Krusell and Smith, which achieves an improved fit in the upper tail of the wealth distribution by assuming that individual discount factors are idiosyncratic. The second is the model of Castañeda et al. (2003), which assumes extremely volatile uninsurable idiosyncratic shocks to labor income. Both models achieve their better fits by introducing individual-specific exogenous disturbances, which arguably weakens the models as explanations of the wealth distribution. ${ }^{2}$ The reason that these models do poorly in explaining the facts is that the only motive to save is precautionary: in order to smooth consumption, agents build a buffer stock of wealth. However, as discussed in the literature on precautionary savings, once the buffer has reached a certain level, the incentive to save becomes weak. The introduction of life-cycle features, as in Huggett (1996), increases the concentration of wealth as measured by the Gini index. However, the life-cycle model generates this higher concentration of wealth by increasing the proportion of households with zero or negative wealth, rather than by generating a higher concentration at the top of the distribution. Therefore, there must be other mechanisms inducing some agents to accumulate and maintain very high levels of wealth.

Entrepreneurship has been recently used to study household savings, the distribution of wealth, and social mobility; see Quadrani (2001), Fernández-Villaverde et al. (2003; henceforth FGC), Gentry and Hubbard (2004), and Cagetti and De Nardi (2006). In the data, entrepreneurs are a small fraction of the population, but have a high saving rate and hold a large share of total wealth. For instance, in the 1989 SCF, entrepreneurs are $8.7 \%$ of the sample, but hold $39 \%$ of total net worth. Both Quadrini (2001) and Gentry and Hubbard (2004) document that the large wealth holdings of entrepreneurs are due not only to the fact that entrepreneurs earn more income, but also to their saving a larger fraction of their income than nonentrepreneurs. Evans and Jovanovic (1989) is another influential work. They show that wealthier people are more inclined to become entrepreneurs because of liquidity constraints: capital is essential for starting a firm, and liquidity constraints tend to exclude those with insufficient funds at their disposal. It will be shown that our quantitative results can also confirm their empirical result.

The model in this paper is constructed along the line of heterogeneous-agent models originally developed by Aiyagari (1994) and is closely related to that 
studied in FGC (2003). In FGC (2003), the interest and wage rates are set exogenously in solving individuals' optimization problems; in other words, their model cannot generate the equilibrium interest and wage rates. In contrast, in this paper, we assume that there are two production sectors (the corporate sector and the entrepreneur sector) and the interest and wage rates can be determined by the production of the corporate sector in equilibrium. This novel feature, together with other features such as uninsurable idiosyncratic risks, occupational choices, and capital market imperfections, makes our model more difficult to solve because the equilibrium factor prices now depend on both aggregate capital stock and aggregate labor employment in the corporate sector, which are not simple functions of a known moment of the distribution, as they depend on the current optimal decisions of all entrepreneurs and workers. Therefore, we need to add some extra steps to guarantee that all markets are clear and all households know the current factor prices before they make decisions.

After calibrating and solving our benchmark model, we find that the model can generate the wealth distribution observed in the U.S. data. Furthermore, we show that due to uninsurable entrepreneurial risks and capital market imperfections, agents choose to save more to undertake entrepreneurial activity. Finally, we find that the economy with more volatile entrepreneurial risks generates greater wealth inequality. The paper is organized as follows. In Section 2, we characterize the model economy. In Section 3, we characterize households' optimization problems and define the recursive competitive equilibrium. In Section 4, we set the parameter values and present main findings. Section 5 concludes.

\section{THE MODEL ECONOMY}

The model economy is populated by a continuum of infinitely lived households measured by 1 . In each period, every household makes a decision to establish or run its own business (be an entrepreneur) or to be a worker who supplies his or her labor to the competitive labor market. There are three sectors in the model: the household sector, the production sectors (the corporate and noncorporate/entrepreneurial sectors), and the financial intermediation sector. The workers face partially uninsurable labor income risk, and the entrepreneurs face idiosyncratic uninsurable entrepreneurial risk. There is one final good that can be used either for consumption or for capital services. The timing of the economy is as follows: (i) At the beginning of each period, different idiosyncratic shocks are realized; (ii) then, the households will produce according to their occupational choices made in the previous period to be entrepreneurs or workers; (iii) next, depending on their present shocks and their access to the credit market, they will decide if they want to become entrepreneurs or workers in the next period by comparing their conditional expectations of the next period's value functions; (iv) finally, after production, households decide how much to save and consume. And all markets clear. 


\subsection{The Household Sector}

Preferences. We consider a model economy with a continuum (with the measure of 1) of ex ante identical, infinitely lived households. Households have standard preferences over consumption and leisure and maximize the expected lifetime utility as follows:

$$
E_{0}\left[\sum_{t=0}^{\infty} \beta^{t} u\left(c_{t}\right)\right],
$$

where $c_{t}$ is current consumption, $u\left(c_{t}\right)=\frac{c_{t}^{1-\sigma}-1}{1-\sigma}$ is the standard CRRA utility function (note that when $\sigma=1, u\left(c_{t}\right)=\log c_{t}$ ), and $\beta \in(0,1)$ is the discount factor.

Households' economic activities. Households are assumed to engage in two economic activities: production according to their occupational choices and wealth accumulation. Here we assume that a fixed cost to be an entrepreneur (measured in utility units) is a fixed number, which will be calibrated later, and occupational choices cannot be reverted in the same period.

Idiosyncratic risk to labor productivity and entrepreneurial skills. Following Aiyagari (1994), we also assume the workers face idiosyncratic shocks to labor efficiency. Each agent is endowed with one unit of time. This unit of time has stochastic productivity as labor input, $\varepsilon$; it can take a value from $\Omega_{w}=\left\{\varepsilon_{1}, \ldots, \varepsilon_{n}\right\}$, where $\varepsilon_{1}<\cdots<\varepsilon_{n}$. When $\varepsilon=\varepsilon_{n}$, we think of the agent as having the highest labor productivity, and when $\varepsilon=\varepsilon_{1}$, we think of him on her as having the lowest labor productivity. The nonzero labor services can be used in his or her own business (to be an entrepreneur) or supplied to the labor market at the competitive wage rate. Following Quadrini (2001), we also assume that labor has the same productivity in both activities and supplies all the services of labor in the market.

For comparison with the shocks to labor efficiency, which takes on additive form, we assume entrepreneurs also face idiosyncratic entrepreneurial risks that take a multiplicative form and are drawn randomly from the set $\Omega_{e}=\left\{\theta_{1}, \ldots, \theta_{N}\right\}$, and similarly we assume that $\theta_{1}<\cdots<\theta_{N}$. Following FGC (2003), the distribution of these two idiosyncratic shocks depends on the agent's past shocks as well as on occupational choices in the last period: If the agent was an entrepreneur (a worker) in the last period $t-1$ and remains an entrepreneur (a worker) in the current period $t$, he or she will draw an entrepreneurial shock (a labor productivity shock) from a first-order Markov chain $P\left(\theta_{t} \mid \theta_{t-1}\right)\left(Q\left(\varepsilon_{t} \mid \varepsilon_{t-1}\right)\right)$ defined on $\Omega_{e}\left(\Omega_{w}\right)$; if the agent was an entrepreneur (a worker) in the last period $t-1$ and wants to be a worker (an entrepreneur) in the current period $t$, he will draw a labor productivity shock (an entrepreneurial shock) from a probability distribution $\widetilde{Q}\left(\varepsilon_{t}\right)\left(\widetilde{P}\left(\theta_{t}\right)\right)$ defined on $\Omega_{w}\left(\Omega_{e}\right)$.

\subsection{The Production Sectors}

As in Quadrini (2001) and Cagetti and De Nardi (2006), we have two production sectors: the corporate sector, composed of large firms and corporations, and the 
noncorporate sector, composed of entrepreneurs. The two sectors differ in their production technologies. Suppose that entrepreneurship is formed by running business projects, and entrepreneurs face uninsurable entrepreneurial risks and financial constraints. The first factor causes the whole household wealth to be invested in the business, and the second one makes the demand for capital of these small firms closely dependent on the net worth of the owners.

The noncorporate sector/entrepreneur sector. The production function in the entrepreneur sector is

$$
y=f(\theta, k, l)=\theta k^{\mu} l^{\omega}, \quad 0<\mu+\omega<1,
$$

where $\theta$ is the entrepreneurial ability/productivity, i.e., the capacity to invest capital productively, $k$ the individual entrepreneurial capital, and $l$ the labor input. Entrepreneurs can borrow and invest capital in a technology whose return depends on their own entrepreneurial ability. That is, those with higher ability levels have higher average and marginal returns from investing.

The corporate sector. The corporate sector is populated by large firms with a standard Cobb-Douglas technology,

$$
Y_{c}=F\left(K_{c}, L_{c}\right)=K_{c}^{\alpha} L_{c}^{1-\alpha},
$$

where $K_{c}$ and $L_{c}$ are aggregate corporate capital and labor, respectively. In equilibrium, the interest rate and the wage rate are given by the marginal products of each factor,

$$
W\left(K_{c}, L_{c}\right)=(1-\alpha)\left(K_{c} / L_{c}\right)^{\alpha} \text { and } R\left(K_{c}, L_{c}\right)=\alpha\left(K_{c} / L_{c}\right)^{\alpha-1}-\delta_{c},
$$

respectively, where $\delta_{c}$ is the rate of depreciation in the corporate sector.

\subsection{The Financial Intermediation Sector}

The financial intermediation sector in this model can collect deposits from households by paying the interest rate $R$ and make loans to either entrepreneurs asking for funds or the corporate sector. The lending is based on a constant-returns-to scale technology with a proportional cost per unit of funds lent. Competition among banks makes (i) intermediation profits zero, (ii) the lending rates equal to $R$ for loans to the corporate sector, and (iii) $R^{e}=R+\eta$ for loans to entrepreneurs; here $\eta$ is the proportional cost per unit of funds faced by entrepreneurs. Based on the data about household borrowing and lending to banks and other intermediation sectors in Quadrani (2001), the lending rate could be set around $(0.035,0.055)$.

\subsection{Demand for Capital and Business Profits}

As a result of borrowing constraints, firms cannot operate at the level that maximizes their profits. Because household asset holdings, used as collateral, determine 
the tightness of these constraints, the demand for capital and labor will depend both on shocks and on the level of asset holdings. In case the borrower does not repay the loan with the interest, i.e., in the case of bankruptcy, the bank gets a share $0<\kappa<1$ of the profits of the firm. This amount can be regarded as the quantity that the bank will get if it uses the legal system to enforce the contract. In addition, the bank cannot seize the household's assets. Finally, a default decision today does not have a reputational consequence in the future. Therefore, the bank will only lend an amount such that the firm does not have any incentive to default, and this amount may not be the one needed by the entrepreneur to operate the firm at an optimal level.

At the beginning of the current period, after observing the shocks, the entrepreneur decides his demand for inputs to maximize his profits:

$$
\begin{aligned}
\pi(\theta, a)= & \max _{\left\{k_{t}, b_{t}, l_{t}\right\}}\left\{\theta k^{\mu} l^{\omega}-W l-\left(R^{e}+\delta_{e}\right) b\right\} \\
& \text { s.t. }: k_{t} \leq a_{t}+b_{t}, \\
\pi(\theta, a) \geq & (1-\kappa) \pi(\theta, a)+\left(1+R^{e}\right) b,
\end{aligned}
$$

where $a_{t}$ is asset holding, $b_{t}$ is the quantity borrowed from banks, $k_{t}$ is the demand for capital, and $\delta_{e}$ is the depreciation rate in the entrepreneurial sector. The second equation above is the incentive compatibility constraint, which implies that the total profit an entrepreneur needs is higher than the entrepreneur's income if he defaults. Thus, we cannot observe any default in equilibrium. The first term on the right-hand side of that equation is the profit that the household keeps for itself, and the second term is the amount of payments to the financial intermediary because of default. Using the same procedure as in FGC (2003), ${ }^{3}$ we can solve the above problem and derive the demand for inputs as well as the profit function: $k=k_{e}(\theta, a), l=l_{e}(\theta, a)$, and $p=\pi(\theta, a)$.

\section{HOUSEHOLD OPTIMIZATION PROBLEMS AND STEADY STATE EQUILIBRIUM}

In this section, we first present households' optimization problems and then define a steady state equilibrium for the economy. The optimal occupational choice and decision problem for a worker can be characterized by the stochastic Bellman equation

$$
\begin{gathered}
v_{w}(a, \varepsilon ; \Gamma)=\max ^{\prime}\left\{u(c)+\beta \max \left[\int v_{w}\left(a^{\prime}, \varepsilon^{\prime} ; \Gamma^{\prime}\right) Q\left(\varepsilon, d \varepsilon^{\prime}\right),\right.\right. \\
\left.\left.\int v_{e}\left(a^{\prime}, \theta^{\prime} ; \Gamma^{\prime}\right) \widetilde{P}\left(d \theta^{\prime}\right)-\psi\right]\right\} \\
\text { s.t.: } c+a^{\prime}=\left(1+R\left(K_{c}, L_{c}\right)\right) a+W\left(K_{c}, L_{c}\right)(1-\widetilde{h}) \varepsilon
\end{gathered}
$$


and $a^{\prime} \geq \bar{a}$, where $\Gamma$ denotes the current distribution of agents over asset holdings and idiosyncratic shocks. The worker makes occupational choices by comparing the conditional expectations of two value functions for being a worker and being an entrepreneur in the next period. We denote the worker's decision rules for consumption and asset holdings as $c=c_{w}(a, \varepsilon)$ and $a^{\prime}=a_{w}(a, \varepsilon)$, respectively.

Similarly, the optimization problem of an entrepreneur can be characterized by

$$
\begin{aligned}
& v_{e}(a, \theta ; \Gamma)=\max _{c}\left\{u(c)+\beta \max \left[\int v_{w}\left(a^{\prime}, \varepsilon^{\prime} ; \Gamma^{\prime}\right) \widetilde{Q}\left(d \varepsilon^{\prime}\right),\right.\right. \\
& \left.\left.\int v_{e}\left(a^{\prime}, \theta^{\prime} ; \Gamma^{\prime}\right) P\left(\theta, d \theta^{\prime}\right)-\psi\right]\right\} \\
& \text { s.t. }: c+a^{\prime}=\pi(\theta, a)+\left[1+R\left(K_{c}, L_{c}\right)\right] a+W\left(K_{c}, L_{c}\right)(1-\widetilde{h})
\end{aligned}
$$

and $a^{\prime} \geq \bar{a}$, where we denote the entrepreneur's decision rules for consumption and asset holdings as $c=c_{e}(a, \theta ; \Gamma)$ and $a^{\prime}=a_{e}(a, \theta ; \Gamma)$, respectively. An entrepreneur will remain an entrepreneur in the next period if $\int v_{w}\left(a^{\prime}, \varepsilon^{\prime} ; \Gamma^{\prime}\right) \widetilde{Q}\left(d \varepsilon^{\prime}\right)<\int v_{e}\left(a^{\prime}, \theta^{\prime} ; \Gamma^{\prime}\right) P\left(\theta, d \theta^{\prime}\right)-\psi$; otherwise, he will choose to be a worker. Similarly, a worker will remain a worker in the next period if $\int v_{w}\left(a^{\prime}, \varepsilon^{\prime} ; \Gamma^{\prime}\right) Q\left(\varepsilon, d \varepsilon^{\prime}\right)>\int v_{e}\left(a^{\prime}, \theta^{\prime} ; \Gamma^{\prime}\right) \widetilde{P}\left(d \theta^{\prime}\right)-\psi$. Define $\chi_{i}(a, \varepsilon, \theta ; \Gamma)$ as the decision rules governing whether an agent stays in the same occupation. We can use the following indicator function to specify occupational choices:

$$
\chi_{i}(a, \varepsilon, \theta ; \Gamma)= \begin{cases}0 & \text { if he stays in the same occupation } \\ 1 & \text { otherwise }\end{cases}
$$

where $i=w, e$.

DEFINITION. A recursive competitive equilibrium for the steady state economy is a set of decision rules, $c_{w}, c_{e}, a_{w}, a_{e}, k, l, K_{c}$, and $L_{c}$, and a set of value functions, $v_{w}$ and $v_{e}$, the pricing functions, $R$ and $W$, and a law of motion for the measure of agents, $H$, such that

(1) The decision rules, $c_{w}$ and $a_{w}$, and value function, $v_{w}$, solve problem (7), given the functions $v_{e}, R, W$, and $H$.

(2) The decision rules, $a_{e}, a_{e}, k, l$, and value function, $v_{e}$, solve problem (8), given the functions $v_{w}, R, W$, and $H$.

(3) The occupational decision rule, $\chi_{i}$, is determined by (9), given $v_{w}$ and $v_{e}$.

(4) $R$ and $W$ are competitive, i.e., they are equal to the marginal productivity of capital and labor (net of depreciation) in the corporate sector.

(5) The firms' decision rules, $k$ and $l$, solve problem (4).

(6) Prices are such that capital and labor markets clear: ${ }^{4}$

$$
\int k d \Gamma_{e}+K_{c}=\int a d \Gamma \quad \text { and } \quad \int l d \Gamma_{e}+L_{c}=\int(1-\tilde{h}) \varepsilon d \Gamma_{w} .
$$

(7) The law of motion for the distribution is consistent with individual optimal behavior, and it is invariant. 
Although we cannot guarantee theoretically the existence and uniqueness of the equilibrium described above because of the nonconvexity problem in the household problem, practically, existence and uniqueness do hold in this model because the computational evidence shows that the value functions in this model are strictly concave for all reasonable parameter choices. This conclusion, together with the assumptions for stochastic shocks, can guarantee the existence of the unique invariant measure.

\section{MAIN FINDINGS}

\subsection{Parameterization}

The quantitative properties of the model's competitive equilibrium cannot be established analytically, and they need to be studied using numerical methods. Computing the recursive competitive equilibrium involves three steps. First, we need to impose restrictions on the functional forms. Second, we select as many parameters as possible either by matching long-run properties of the model economy to the U.S. data or by using previous empirical evidence. In the last step, we need to develop a numerical algorithm to solve the competitive equilibrium up to an arbitrarily small error. Our computational algorithm is a combination of the ones used in FGC (2003), Young (2006), and Luo and Young (2009). ${ }^{5}$ The model period is set to one year, which is standard in the literature. The discount factor, $\beta$, is set together with the share of capital in the entrepreneurial sector, $\mu$, so that the capital-output ratio of the whole economy in the steady state is equal to 2.5. We set $\alpha=0.36$, which is the standard choice in the literature, and $\mu=0.36$ and $\omega=0.52$ so that $\mu+\varpi=0.88<1 .{ }^{6}$ The implicit degree of decreasing returns to scale (12\%) generates a portion of income earned by entrepreneurs that matches the PSID data. In our benchmark exercise, we set $\phi=0$. We also choose the parameter $\psi$, which governs the amount of effort to be an entrepreneur, to be 0.5 . In this way, the number of entrepreneurs is around $8.6 \%$, which matches the number in the U.S. data (SCF and PSID). Table 1 summarizes our parameter choices for the baseline model.

TABLE 1. Parameter choices

\begin{tabular}{ll}
\hline Parameter & Value \\
\hline$\beta$ & 0.9 \\
$\sigma$ & 1 \\
$\alpha$ & 0.36 \\
$\delta$ & 0.06 \\
$\mu$ & 0.36 \\
$\omega$ & 0.52 \\
$\eta$ & 0 \\
$\psi$ & 0.5 \\
\hline
\end{tabular}


TABLE 2. Idiosyncratic shocks to labor productivity

$$
\varepsilon=\left[\begin{array}{lll}
0.57 & 0.93 & 1.51
\end{array}\right], P=\left[\begin{array}{lll}
0.75 & 0.24 & 0.01 \\
0.19 & 0.62 & 0.19 \\
0.01 & 0.24 & 0.75
\end{array}\right], p=\left[\begin{array}{lll}
0.31 & 0.38 & 0.31
\end{array}\right]
$$

Next, to parameterize the stochastic idiosyncratic labor productivity, we follow Storesletten et al. (2007). They argue that the specification of labor income for an individual household must allow for persistent and transitory components. Based on their empirical work from the PSID data, we specify $\log \left(y_{i}\right)$ to be

$$
\begin{aligned}
\log \left(y_{i}\right) & =\omega_{i}+\epsilon_{i}, \\
\omega_{i}^{\prime} & =\rho \omega_{i}+v_{i}^{\prime},
\end{aligned}
$$

where $\epsilon_{i} \sim N\left(0, \sigma_{\epsilon}^{2}\right)$ is the transitory component and $\omega_{i}$ is the persistent component. The innovation term associated with $\omega_{i}$ is assumed to be distributed as $N\left(0, \sigma_{v}^{2}\right)$. They estimate $\rho=0.935, \sigma_{\epsilon}^{2}=0.01$, and $\sigma_{v}^{2}=0.061$. The unconditional variance of $\log \left(y_{i}\right)$ is then $\operatorname{var}\left[\log \left(y_{i}\right)\right]=\frac{\sigma_{\epsilon}^{2}}{1-\rho^{2}}+\sigma_{v}^{2}=0.14051$. This process attributes about half the unconditional variance to the persistent component and half to the transitory component. We then approximate this process with a three-state Markov chain, which is characterized in Table 2.

For the points in $\theta$, we follow Quadrini (2001) and FGC (2003). Conditional on $\theta_{1}, \theta_{2}$ and $\theta_{3}$ are set to obtain the demand for capital in the medium shock to be 10 times larger than that in the low shock and for firms in the high shock to be 100 times larger. Finally, $\theta_{1}$ is set to make the ratio of entrepreneurial wealth to total wealth in the economy match around 0.4. In Table 3 , we choose the diagonal elements in $Q$ to match the empirical exit and entry rates from entrepreneurship, although we cannot reach the high exit rate as reported in the data, which is around $24 \%$. In the nondiagonal parts, for the low shocks, we divide the rest of the probability into two equal numbers, 0.16 each; for the medium shock, we set them to capture the growth of the firms; for the high shocks, we just assume they drop to the medium level of $10 \%$. The choice of $q=\left[\begin{array}{lll}0.6 & 0.3 & 0.1\end{array}\right]$ is motivated by Quadrini (2001), who he chooses three bins that assign $60 \%$ of entrepreneurs to small projects, $30 \%$ to middle-sized projects, and $10 \%$ to large projects, respectively.

TABLE 3. Idiosyncratic shocks to entrepreneurial activity

$$
\theta=\left[\begin{array}{lll}
1 & 1.26 & 1.68
\end{array}\right], Q=\left[\begin{array}{lll}
0.68 & 0.16 & 0.16 \\
0.1 & 0.7 & 0.2 \\
0.0 & 0.1 & 0.9
\end{array}\right], q=\left[\begin{array}{lll}
0.6 & 0.3 & 0.1
\end{array}\right]
$$




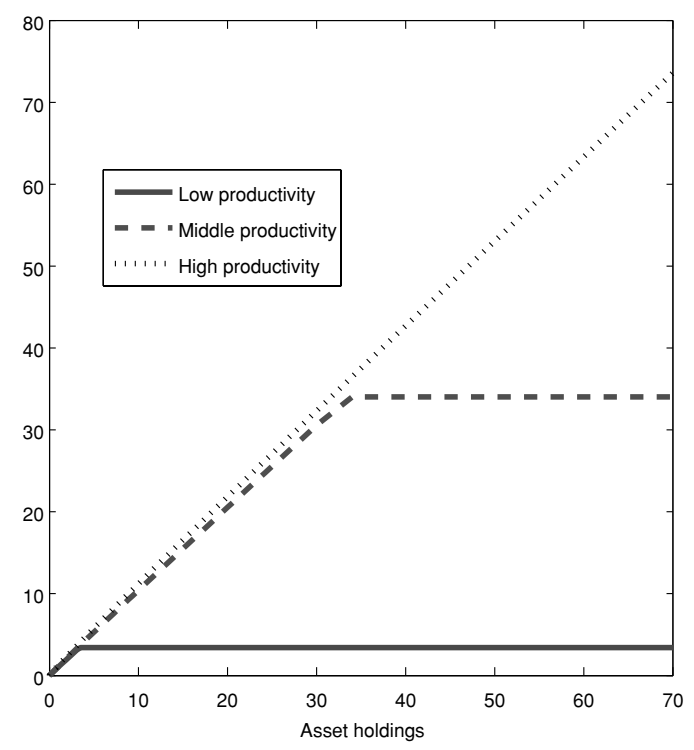

FIGURE 1. The demand for capital.

\subsection{Baseline Results}

As in FGC (2003), our model with endogenously determined interest and wage rates also predicts that the firms are always constrained in their financial decisions in the range of asset holdings where the measure of households is positive. It is obvious that entrepreneurs can borrow more from outside and operate more profitably if their own asset holdings are high. Figure 1 shows the constrained demand for capital. The difference between the demand for capital and the $45^{\circ}$ line is the amount they can borrow from banks. It clearly shows that the higher the wealth holdings of the entrepreneurs, the higher the capital they demand. That is, they will run larger projects. Figure 2 shows that the level of profits increases with asset holdings until the firm can operate at the optimum level.

The value functions for workers and entrepreneurs are plotted in Figures 3 and 4, respectively. Theoretically, it is obvious that occupational choices of the households may make the value functions nonconcave, because an individual cannot be half an entrepreneur and half a worker. However, these two figures show that the value functions for workers and entrepreneurs are both strictly concave. This finding is robust for any set of our parameter choices, and is consistent with that obtained in Gomes et al. (2001) and FGC (2003). Theoretical departures from concavity are not a serious problem.

Another important question in the literature about entrepreneurship is who prefers to be an entrepreneur and run his own projects. As in FGC (2003), we also find that those households with asset holdings in the middle of the distribution are most likely to become entrepreneurs, because they can borrow enough capital and 


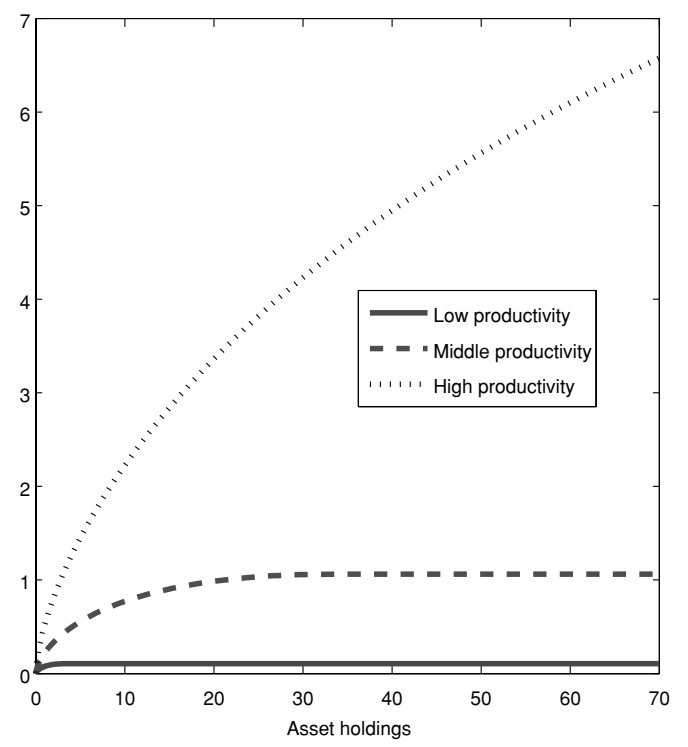

FIGURE 2. The profits.

run more profitable projects, whereas households with low asset holdings prefer to be workers because they cannot borrow enough capital due to the borrowing constraints. In contrast, for households with high levels of asset holdings, running

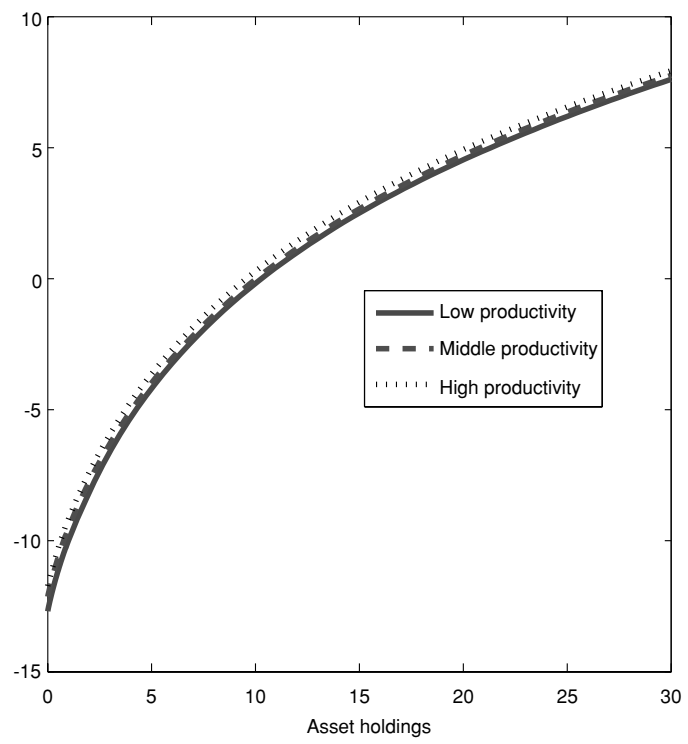

FIGURE 3. Worker's value function. 


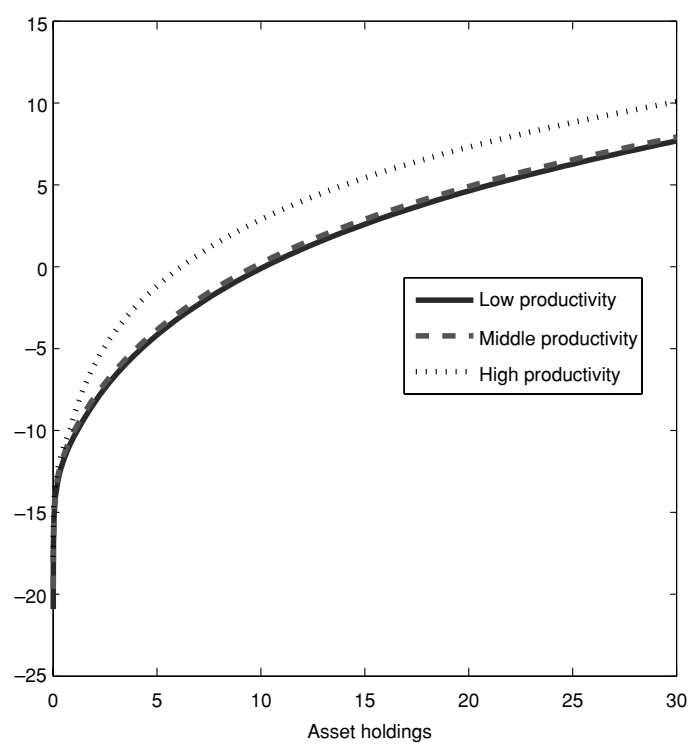

FIGURE 4. Entrepreneur's value function.

their own businesses is not very attractive because they can earn enough interest income from their own assets. Furthermore, our model also predicts that the percentage of workers is much larger than that of entrepreneurs, and most workers hold assets less than 5, whereas most entrepreneurs hold assets less than 20 . That is, uninsurable idiosyncratic risks and capital market imperfections make households that want to become entrepreneurs accumulate large wealth.

\subsection{Implications of Entrepreneurial Risk on Wealth Inequality and Aggregate Activity}

Figure 5 clearly shows how our model can generate a skewed wealth distribution. Compared with the Aiyagari model, our benchmark model can fit the data much better. In our model, the top $1 \%, 5 \%$, and $10 \%$ of agents hold $22 \%, 49 \%$, and $63 \%$ of wealth, respectively; these numbers are quite similar to those reported from the U.S. data (26\%, 47\%, and 60\%, respectively). As we discussed above, it is difficult to estimate or calibrate the stochastic process of entrepreneurial risk because of the lack of good micro data. Therefore, to examine the effects of entrepreneurial risk on both the wealth distribution and aggregate activity, we assume that the entrepreneurial risk follows an $A R(1)$ process. Hence, in this section, we just study how the changes in the volatility of entrepreneurial risk affect the economy instead of trying to match the data perfectly. Specifically, we assume that the entrepreneurial shock follows an $A R(1)$ process,

$$
\theta_{i}^{\prime}-\bar{\theta}=\rho_{e}\left(\theta_{i}-\bar{\theta}\right)+\zeta_{i},
$$




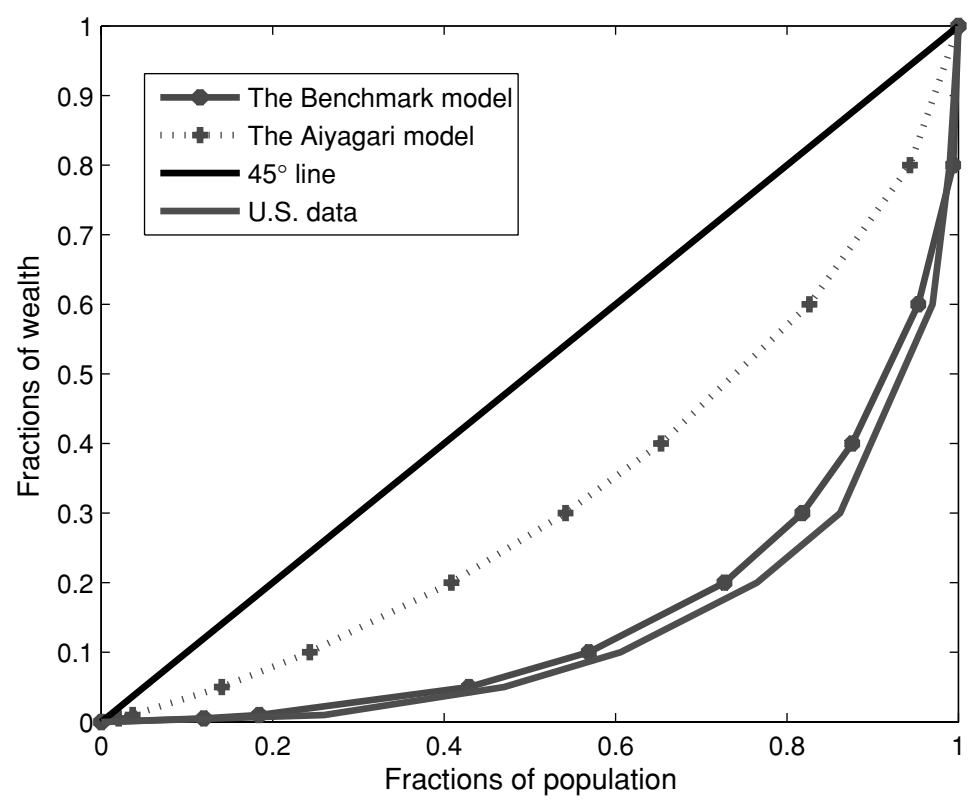

FigURE 5. The Lorenz curves for wealth.

where $\bar{\theta}=1.55, \rho_{e}=0.65$, and $\zeta_{i} \sim N\left(0, \sigma_{\zeta}^{2}\right){ }^{7}$ We then approximate this process with a three-state Markov chain as we did before.

Table 4 and Figure 6 provide a summary of the effects of the entrepreneurial risks on aggregate quantities and wealth inequality. The table shows that in the economy with uninsurable entrepreneurial risks, both entrepreneurial capital and aggregate capital increase with the volatility of the entrepreneurial shock because of the precautionary savings motive and borrowing constraints. This mechanism of wealth accumulation is similar to the one in the Bewley-Aiyagari economies. In addition, the equilibrium interest rate is decreasing with $\sigma_{\zeta}^{2}$ as the entrepreneurial risk also increases the ratio $K_{c} / L_{c}$. It is shown in a one-sector growth model of Angeletos and Calvet (2006) that idiosyncratic production shocks introduce a risk premium on private capital and reduce the demand for investment. Our model tells another story. In our setup, although the introduction of entrepreneurial risks reduces the demand for the investment in the entrepreneur sector because of a

TABLE 4. The aggregate effects of uninsurable entrepreneurial risks

\begin{tabular}{rcrrccccc}
\hline$\sigma_{\zeta}$ & $K$ & $K_{e}$ & $K_{c} / L_{c}$ & $Y_{e}$ & $Y_{c}$ & \# of entrep. & $R$ & $W$ \\
\hline 0.14 & 1.380 & 0.176 & 4.225 & 0.117 & 0.482 & $6.0 \%$ & 0.087 & 1.075 \\
0.16 & 1.554 & 0.304 & 5.169 & 0.207 & 0.441 & $9.6 \%$ & 0.069 & 1.157 \\
0.18 & 1.688 & 0.642 & 10.684 & 0.454 & 0.233 & $17.8 \%$ & 0.021 & 1.511 \\
\hline
\end{tabular}




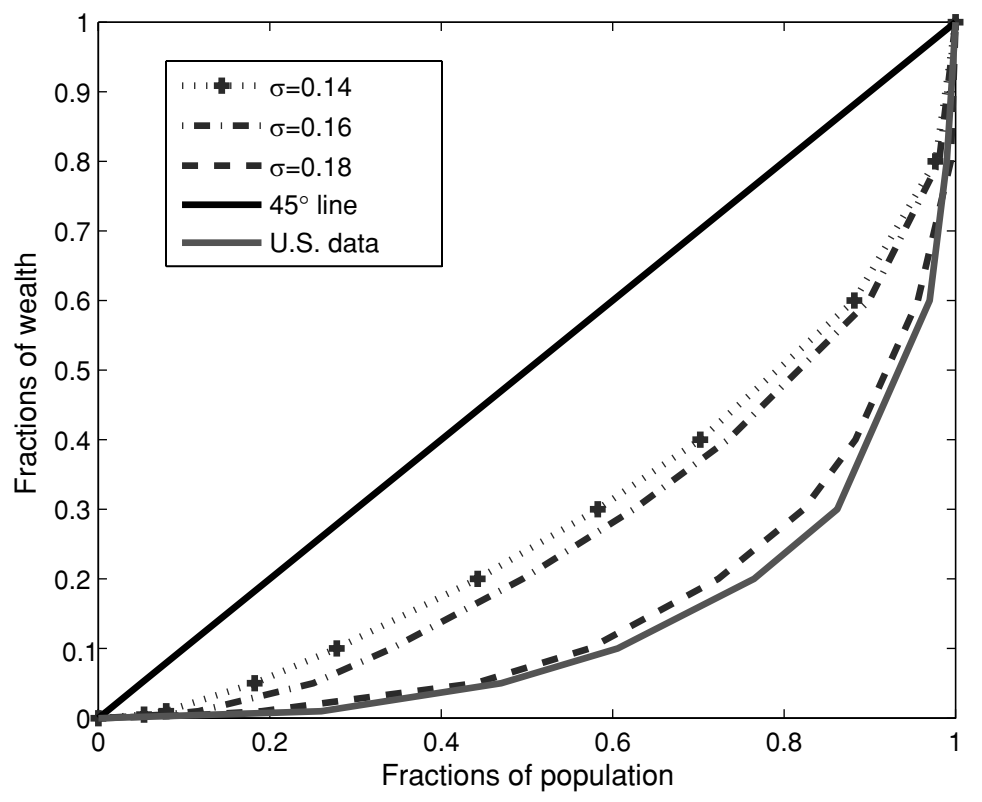

FIGURE 6. The Lorenz curves for wealth.

risk premium on private capital, the effect of the precautionary savings motive dominates. Therefore, the economy with higher volatility may be characterized by higher entrepreneurial capital due to the net effect of precautionary savings, a risk premium of private capital, a lower risk-free rate, and higher aggregate capital due to the reallocation of capital and labor in the two sectors. Table 4 also shows that the fraction of entrepreneurs in the economy is increasing with $\sigma_{\zeta}^{2}$. The intuition is simple: entrepreneurs with higher wealth levels can borrow more funds and run more profitable projects; in this case choosing to be an entrepreneur becomes more attractive. Furthermore, the economy with high volatility of entrepreneurial risks will generate greater wealth inequalities. Figure 6 plots the Lorenz curves for different volatilities. Our model's prediction is very intuitive: for the economy with high volatility, the entrepreneurs hit by a sequence of good shocks will become wealthier and those hit by a sequence of bad shocks will keep losing and then have to close their own businesses and become workers.

\subsection{Effects of Imperfect Enforcements}

In this section, we examine the impacts of contract enforcements on the economy by adjusting the appropriability factor $\kappa$. This factor may also be a measure of the degree of financial development in the equilibrium. Based on the number reported by Moddy's investors' service, we set $\kappa=0.4,0.6$, and 0.8 , respectively. All other parameters are the same as those used in the baseline model. Table 5 summarizes the main effects of $\kappa$, i.e., the tightness of the borrowing constraints, 
TABLE 5. The aggregate effects of contract enforcements

\begin{tabular}{ccccccccc}
\hline$\kappa$ & $K$ & $K_{e}$ & $K_{c} / L_{c}$ & $Y_{e}$ & $Y_{c}$ & \# of entrep. & $R$ & Gini \\
\hline 0.4 & 1.912 & 0.820 & 7.690 & 0.422 & 0.300 & $8.23 \%$ & 0.039 & 0.638 \\
0.6 & 1.961 & 0.932 & 8.366 & 0.473 & 0.268 & $9.53 \%$ & 0.035 & 0.635 \\
0.8 & 1.973 & 1.023 & 8.716 & 0.512 & 0.240 & $10.3 \%$ & 0.033 & 0.627 \\
\hline
\end{tabular}

on aggregate quantities and cross-sectional properties. This table shows that, when $\kappa$ increases, i.e., the borrowing constraints become tight, both $K$ and $K_{e}$ go up. The intuition behind this result is simple: in the economy with an high appropriability factor, in equilibrium, where no default is observed, entrepreneurs could borrow more capital and employ more labor, and then run more profitable projects and produce more output in the entrepreneurial sector. Furthermore, more workers with higher levels of asset holdings would choose to be entrepreneurs. This effect can slightly reduce the wealth inequalities in the economy because more people become entrepreneurs, and more entrepreneurs become even richer.

\section{CONCLUSIONS}

This paper presents and solves a heterogeneous-agent general equilibrium model with occupational choices, uninsurable idiosyncratic labor and entrepreneurial risks, and incomplete markets including both the absence of a state-contingent market for idiosyncratic risks and credit market imperfections. We demonstrate in this model that introducing entrepreneurial risks and capital market imperfections can substantially increase the wealth inequalities and thus provide a better match with the U.S. data. We also demonstrate that uninsurable entrepreneurial risk can increase aggregate entrepreneurial capital stock because of precautionary motives and borrowing constraints.

\section{NOTES}

1. This number is taken from Budría et al. (2001); the data used are from the Survey of Consumer Finances (SCF), 1998 wave. Previous estimates using different waves of the SCF are quite similar to this number.

2. For a detailed discussion of the successes and failures of these models in accounting for wealth inequality, see a survey by Quadrini and Ríos-Rull (1997).

3. We thank Fernandez-Villaverde for sharing with us his Matlab code for solving the demand functions.

4. Note that the left-hand side of the capital market (labor market) equation is the aggregate capital (labor) demand in the entrepreneurial sector and the corporate sector, and the right-hand side is the aggregate capital (labor) supply from all agents. We also assume here that entrepreneurs do not use their own labor in production activity.

5. It is available from the corresponding author by request.

6. Note that the production function in the corporate sector is the standard Cobb-Douglas one, whereas the one in the entrepreneurial sector is strictly decreasing returns to scale.

7. Changing the values of $\bar{\theta}$ and $\rho_{e}$ does not change our main results reported in Table 4 . 


\section{REFERENCES}

Aiyagari, S. Rao (1994) Uninsured idiosyncratic risk and aggregate saving. Quarterly Journal of Economics 109, 659-684.

Angeletos, George-Marios and Laurent Calvet (2006) Idiosyncratic production risk, growth, and the business cycle. Journal of Monetary Economics 53(6), 1095-1115.

Budría Rodríguez, Santiago, Javier Díaz-Giménez, Vicenzo Quadrini, and José-Víctor Ríos-Rull (2001) Updated facts on the U.S. distributions of earnings, income, and wealth. Federal Reserve Bank of Minneapolis Quarterly Review 26, 2-35.

Cagetti, Marco and Mariacristina De Nardi (2006) Entrepreneurship, frictions and wealth. Journal of Political Economy 114 (5), 835-870.

Castañeda, Ana, Javier Díaz-Giménez, and José-Víctor Ríos-Rull (2003) Accounting for wealth and income inequality. Journal of Political Economy 111, 818-857.

Evans, David S and Boyan Jovanovic (1989) An estimated model of entrepreneurial choice under liquidity constraints. Journal of Polical Economy 97, 808-827.

Fernandez-Villaverde, Jesus, Jose Enrique Galdon-Sanchez, and Luis Carranza (2003) Entrepreneurship, Financial Intermediation and Aggregate Activity. Mimeo, University of Pennsylvania.

Gentry, W. and R. Hubbard (2004) Entrepreneurship and household savings. Advances in Economic Analysis and Policy 4(1).

Gomes, J., J. Greenwood, and S. Rebelo (2001) Equilibrium unemployment. Journal of Monetary Economics 48, 109-152.

Huggett, Mark (1996) Wealth distribution in life cyle economies. Journal of Monetary Economics 38(3), 469-494.

Krusell, Per and Anthony A. Smith, Jr. (1998) Income and wealth heterogeneity in the macroeconomy. Journal of Political Economy 106, 867-896.

Luo, Yulei and Eric R. Young (2009) The wealth distribution and the demand for status. Macroeconomic Dynamics 13 (Suppl. 1), 1-30.

Quadrini, Vincenzo (2001) Entrepreneurship, saving and social mobility. Review of Economic Dynamics $3,1-40$.

Quadrini, Vincenzo and Jose-Victor Ríos-Rull (1997) Understanding the U.S. distribution of wealth. Federal Reserve Bank of Minneapolis Quarterly Review 21, 675-687.

Storesletten, Kjetil, Chris Telmer, and Amir Yaron (2007) Asset pricing with idiosyncratic risk and overlapping generations. Review of Economic Dynamics 10(4), 519-548.

Young, Eric R. (2006) Approximate Aggregation. Mimeo, University of Virginia. 